\title{
The Enzymic Degradation of an Alkali-soluble Glucan from the Cell Walls of Saccharomyces cerevisiae
}

\author{
By G. H. FLEET* AND D. J. MANNERS $\dagger$ \\ Department of Brewing and Biological Sciences, \\ Heriot-Watt University, Edinburgh EHI I $H X$
}

(Received 27 May 1976)

\begin{abstract}
SUMMARY
An alkali-soluble glucan from the cell walls of Saccharomyces cerevisiae NCYCI I 09 has been hydrolysed with a purified endo- $(\mathrm{I} \rightarrow 3)-\beta$-D-glucanase and an endo$(\mathrm{I} \rightarrow 6)-\beta$-D-glucanase from Bacillus circulans $\mathrm{WL}-\mathrm{I} 2$. The products of enzyme action include various oligosaccharide and polysaccharide fractions which have been separated by gel filtration and characterized, giving new information on the fine structure of the glucan. The isolated cell walls have also been subjected to enzymic hydrolysis. The results suggest that part of the cell-wall mannan is held in place by a glucan component.
\end{abstract}

\section{INTRODUCTION}

In a previous paper (Fleet \& Manners, 1976), we described the isolation, composition and general structure of an alkali-soluble glucan component from the cell walls of Saccharomyces cerevisiae. This new wall glucan contained both $(\mathrm{I} \rightarrow 3)-\beta$ and $(\mathrm{I} \rightarrow 6)-\beta$ linkages. The determination of polysaccharide fine structure is greatly facilitated by the judicious use of specific hydrolytic enzymes. Fleet \& Phaff (1974a) reported the purification and properties of an endo-( $\mathrm{I} \rightarrow 3)-\beta$-D-glucanase and an endo-( $\mathrm{I} \rightarrow 6)-\beta$-D-glucanase from Bacillus circulans WL-I 2 suitable for such application. The present paper describes the use of these two enzymes in determining some finer structural features of the alkali-soluble glucan. In addition, the action of these two enzymes on the glucan is compared with their action on intact yeast cell walls. A preliminary account of part of these results has been given (Fleet \& Manners, 1975).

\section{METHODS}

Cell walls and glucan fraction. The isolation of cell walls from $S$. cerevisiae NCYCI IO9 and from baker's yeast and the preparation of the alkali-soluble glucan fraction $G_{1}$ from these walls have been described previously (Fleet \& Manners, 1976).

Analytical procedures. Methods for total and partial acid hydrolysis, glucose and carbohydrate estimation, methylation analysis and paper chromatography were as described by Fleet \& Manners (1976). Protein was determined by the method of Lowry et al. (I95I). Gel filtration of polysaccharide hydrolysates was done either on a column (II $5 \times 1 \cdot 5 \mathrm{~cm}$ ) of Bio-Gel P-2 (BioRad) or on a column $(85 \times \mathrm{I} \cdot 5 \mathrm{~cm})$ of Sepharose 6B (Pharmacia). The columns were equilibrated and eluted with $0.05 \mathrm{M}-\mathrm{NaCl}$. Fractions of $3.0 \mathrm{ml}$ were generally

\footnotetext{
* Present address: Department of Food Technology, University of New South Wales, P.O. Box I, Kensington, New South Wales, 2033, Australia.

$\dagger$ To whom communications should be addressed.
}

Vol. 98, No. I, was issued 19 January 1977 
Table I. The products of glucanase action on $G_{1}$ preparations and yeast $(\mathrm{I} \rightarrow 6)-\beta$-D-glucan

After enzyme action for $4 \mathrm{~h}$, products were identified by paper chromatography using solvent $\mathrm{A}$ (Fleet \& Manners, 1976). The + values refer to the relative spot intensities on the chromatograms. The figures in parentheses are mobility values relative to glucose ( $1 \cdot 0)$.

$$
\begin{aligned}
& (\mathrm{I} \rightarrow 3)-\beta \text {-D-Glucanase } \\
& \text { action on } \mathrm{G}_{1}^{*}
\end{aligned}
$$

Glucose, $10+$

Laminaribiose, $10+(0.76)$

Laminaritriose, $10+(0.5 \mathrm{I})$

Laminaritetraose, $4+(0 \cdot 35)$

Laminaripentaose,

$4+(0.24)$

Gentiotriose, $4+(0 \cdot 18)$

$$
\begin{gathered}
(\mathrm{I} \rightarrow 6)-\beta \text {-D-Glucanase } \\
\text { action on } \mathrm{G}_{1}{ }^{*}
\end{gathered}
$$

Glucose, 4+

Laminaribiose, $\mathrm{I}+(0 \cdot 76)$

Gentiobiose, $10+(0.44)$

Laminaritriose, I + (0.5I)

$3^{2}-\beta$-Glucosylgentiobiose, $4+(0.31)$

Gentiotriose, $4+(0.18)$

Mixed-linkage tetrasaccharide,

$4+(0 \cdot 12)$

Gentiotetraose, $4+(0.08)$
$(\mathrm{I} \rightarrow 6)-\beta$-D-Glucanase action on yeast $(\mathrm{I} \rightarrow 6)-\beta$-D-glucan $\dagger$

Glucose, $6+$

Gentiobiose, 10+

$3^{2}-\beta$-Glucosylgentiobiose, $6+$

Gentiotriose, 10+

Mixed-linkage tetrasaccharide, Io+

Gentiotetraose, IO+

Gentiopentaose, IO+

* $\mathrm{G}_{1}$ preparations from both $S$. cerevisiae NCYCI 109 and baker's yeast gave the same results.

$\dagger$ Preparation obtained from baker's yeast by Manners et al. (1973b).

collected and their carbohydrate content was measured by the phenol-sulphuric acid assay (Dubois et al., 1956).

Glucanase preparations. The $(\mathrm{I} \rightarrow 3)-\beta$ - and $(\mathrm{I} \rightarrow 6)-\beta$-D-glucanases were produced by Bacillus circulans WL-I 2 grown in a salts medium with baker's yeast cell walls as the carbon source. The two enzymes were extensively purified as described by Fleet \& Phaff (I974a). After purification, the enzymes were checked for hydrolytic action and substrate specificity. The $(\mathrm{I} \rightarrow 3)$ - $\beta$-D-glucanase was specific for $(\mathrm{I} \rightarrow 3)$ - $\beta$-D-linked glucans (laminarin) and hydrolysed these molecules in a random manner, i.e. it was an endo-enzyme. The $(\mathrm{I} \rightarrow 3)-\beta$-Dglucanase did not hydrolyse the $(\mathrm{I} \rightarrow 6)-\beta$-D-glucans, pustulan (Hellerqvist, Lindberg \& Samuelsson, I968), or luteose (Nakamura \& Tanabe, 1963). Similarly, the $(\mathrm{I} \rightarrow 6)-\beta$-Dglucanase (which was also an endo-enzyme) was specific for the $(I \rightarrow 6)-\beta$-D-glucosidic linkage and did not release reducing sugars from laminarin. These results are consistent with those previously published (Fleet \& Phaff, 1974a).

Enzymic hydrolysis of $G_{1}$ preparations and cell walls. Before use, cell walls were first heated in water at $100{ }^{\circ} \mathrm{C}$ for $5 \mathrm{~min}$ to inactivate endogenous glucanase activities (Fleet \& Phaff, $1974 b$ ). Cell walls or $\mathrm{G}_{1}$ preparations were uniformly suspended in 0.25 M-sodium succinate buffer $\mathrm{pH} 5^{\circ} \mathrm{O}$ using a Potter homogenizer. Enzyme solution was then added so that, in all cases, the final concentration of the cell walls or $G_{1}$ was $2 \mathrm{mg} \mathrm{ml}^{-1}$ and of the enzyme was 0.5 unit $\mathrm{ml}^{-1}$. All suspensions were made $0.0 \mathrm{I} \%(\mathrm{w} / \mathrm{v})$ with respect to sodium azide as a precaution against microbial contamination. Suspensions were incubated at $30{ }^{\circ} \mathrm{C}$ with slow rotation. When required, samples were removed for the determination of reducing sugar or total carbohydrate solubilization.

\section{RESULTS}

Action of $(\mathrm{I} \rightarrow 3)-\beta$ - and $(\mathrm{I} \rightarrow 6)-\beta$-D-glucanases on fraction $G_{1}$

The $(\mathrm{I} \rightarrow 3)-\beta$-D-glucanase caused immediate and extensive hydrolysis of both $\mathrm{G}_{1}$ preparations (Figs I and 6). Approximately $25 \%$ of the initial glucan material remained insoluble under the conditions of hydrolysis but was readily solubilized on heating. However, this material precipitated again on cooling. The soluble products after hydrolysis for I to 


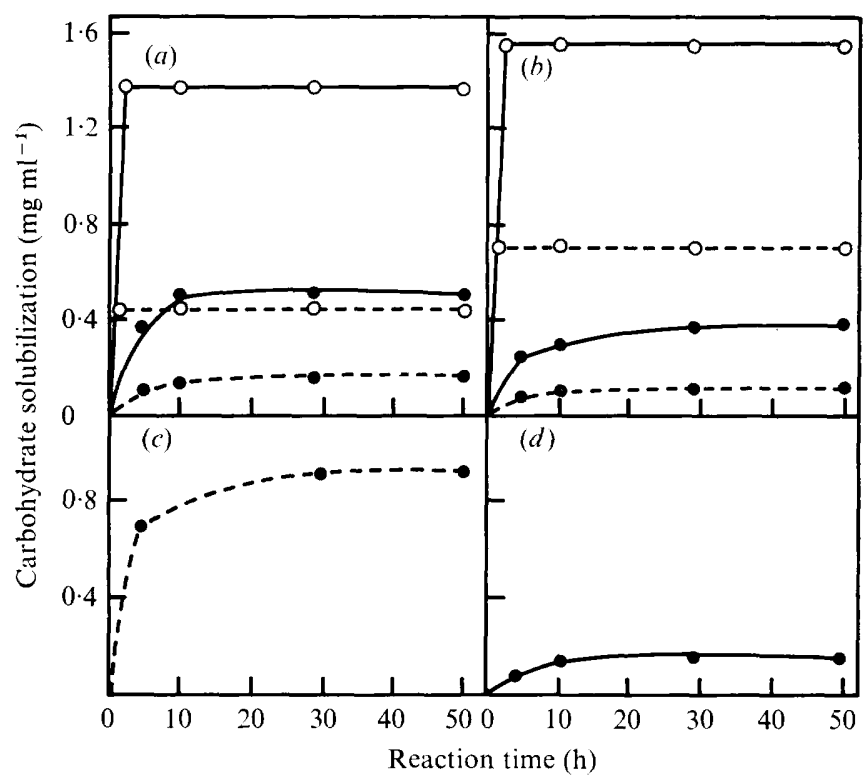

Fig. I. The action of the $(\mathrm{I} \rightarrow 3)-\beta$-D-glucanase $(-)$ and the $(\mathrm{I} \rightarrow 6)-\beta$-D-glucanase $(----)$ on yeast cell-wall glucan preparations: $(a) \mathrm{G}_{1}$ from $S$. cerevisiae NCYCI I09; (b) $\mathrm{G}_{1}$ from baker's yeast; $(c)$ yeast $(\mathrm{I} \rightarrow 6)$ - $\beta$-D-glucan; $(d)$ yeast alkali-insoluble $(\mathrm{I} \rightarrow 3)$ - $\beta$-D-glucan. $\bigcirc$, Release of reducing sugars; $\bigcirc$, total solubilization of carbohydrate.

$4 \mathrm{~h}$ are listed in Table I. Similar products were noted after $50 \mathrm{~h}$ hydrolysis, but the proportions of laminaritetraose and laminaripentaose were much lower and gentiotriose had increased slightly. Gentiobiose was not formed. The presence of gentiotriose was confirmed by the fact that it was hydrolysed by the $(I \rightarrow 6)-\beta$-D-glucanase to give glucose and gentiobiose.

The $\mathrm{G}_{1}$ preparations were also hydrolysed by the $(\mathrm{I} \rightarrow 6)-\beta$-D-glucanase, although to a much lesser extent than by the $(\mathrm{I} \rightarrow 3)-\beta$-D-glucanase (Fig. I $a, b)$. The soluble products of this reaction are also shown in Table $\mathrm{I}$. The proportions of gentiotriose and gentiotetraose were much lower after hydrolysis for $50 \mathrm{~h}$ and the amounts of the two mixed-linkage oligosaccharides $\left(R_{\mathrm{gle}} \mathrm{O} .3 \mathrm{I}\right.$ and $\left.R_{\mathrm{glc}} \mathrm{O} . \mathrm{I2}\right)$ had substantially increased. The presence of laminarisaccharides and mixed-linkage oligosaccharides in the products suggests that some of the $(\mathrm{I} \rightarrow 3)$ - $\beta$-D-linked residues are flanked by certain sequences of $(\mathrm{I} \rightarrow 6)-\beta$-D-linked residues.

These enzymic studies confirm the chemical observations (Fleet \& Manners, 1976) that the $\mathrm{G}_{1}$ wall fraction is a predominantly $(\mathrm{I} \rightarrow 3)-\beta$-D-linked glucan containing a small percentage of $(\mathrm{I} \rightarrow 6)-\beta$-D-linked residues. The latter can exist in blocks of at least three units since gentiotetraose was a product of hydrolysis.

For comparison, Fig. I $(c, d)$ shows the action of the two glucanases on yeast alkaliinsoluble (I $\rightarrow 3$ )- $\beta$-D-glucan (Manners, Masson \& Patterson, I973a) and yeast $(\mathrm{I} \rightarrow 6)$ - $\beta$-Dglucan (Manners et al., 1973b). The alkali-insoluble $(\mathrm{I} \rightarrow 3)-\beta$-D-glucan was only weakly cleaved by the $(\mathrm{I} \rightarrow 3)-\beta$-D-glucanase (giving traces of laminarisaccharides) and was not hydrolysed at all by the $(\mathrm{I} \rightarrow 6)-\beta$-D-glucanase. The yeast $(\mathrm{I} \rightarrow 6)-\beta$-D-glucan was not hydrolysed by the $(\mathrm{I} \rightarrow 3)-\beta$-D-glucanase but was extensively degraded by the $(\mathrm{I} \rightarrow 6)-\beta$-D-glucanase yielding the products shown in Table I. Large amounts of the mixed-linkage oligosaccharides had accumulated after $50 \mathrm{~h}$. The trisaccharide $\left(R_{\mathrm{glc}} 0.3 \mathrm{I}\right)$ was therefore isolated by preparative paper chromatography and identified. Total acid hydrolysis yielded only 


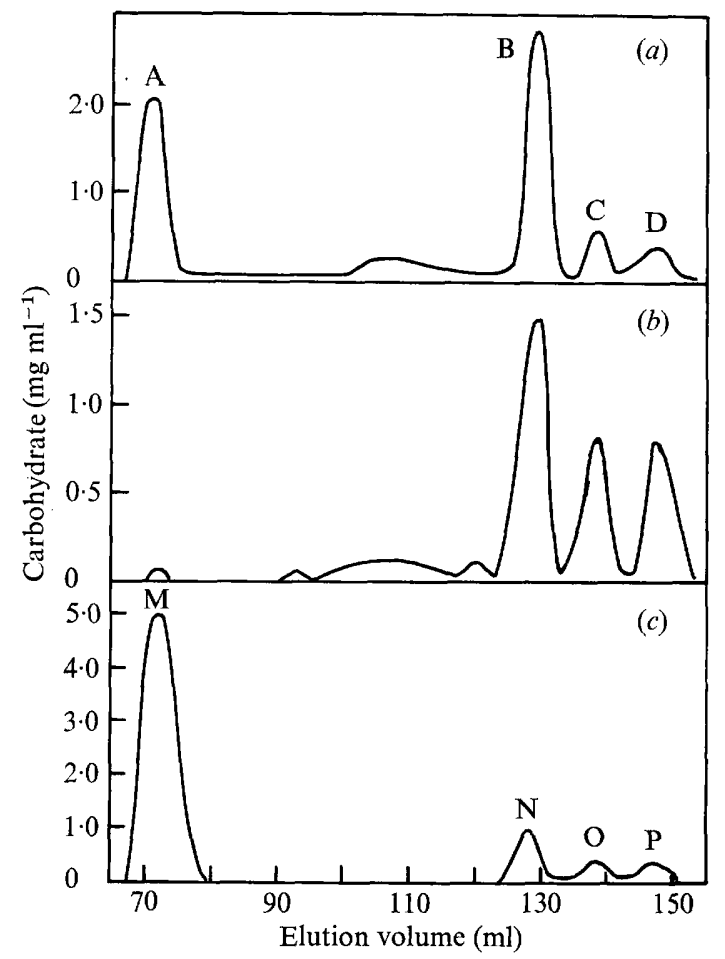

Fig. 2. Bio-Gel P-2 chromatography of $(\mathrm{I} \rightarrow 3)-\beta$-D-glucanase hydrolysates of $(a) \mathrm{G}_{1}$ from $S$. cerevisiae NCYCI I09, (b) $\mathrm{G}_{1-6}$ from $S$. cerevisiae NCYCI I09, (c) cell walls from $S$. cerevisiae NCYCI I09.

glucose; on partial acid hydrolysis, gentiobiose and laminaribiose were formed in addition to glucose. Reduction of the trisaccharide with potassium borohydride, followed by partial acid hydrolysis, yielded glucose and laminaribiose as reducing sugars and sorbitol and gentiobi-itol as non-reducing sugars (Peat, Whelan \& Edwards, 1958). Incubation of the trisaccharide with an exo-(I $\rightarrow 3)-\beta$-D-glucanase (kindly supplied by Dr G. Wilson) produced glucose and gentiobiose. Collectively these results characterize the oligosaccharide as $3^{2}-\beta$ glucosylgentiobiose, as opposed to $6^{2}-\beta$-glucosyllaminaribiose or 3,6 -di- $\beta$-glucosylglucose: $\mathrm{G}^{1}-{ }^{3} \mathrm{G}^{1}-{ }^{6} \mathrm{G}$.

\section{Column chromatography of the $G_{1}$ enzyme hydrolysates}

The total carbohydrate release was far higher than the corresponding reducing sugar value (Fig. I $a, b$ ). This suggested that a proportion of the solubilized products were large molecules. The solubilized material was therefore fractionated by gel filtration.

$(\mathrm{I} \rightarrow 3)-\beta$-D-glucanase hydrolysates. $\mathrm{G}_{1}$ (I00 $\mathrm{mg}$ ) from $S$. cerevisiae NCYCI Io9 was hydrolysed with $(\mathrm{I} \rightarrow 3)-\beta$-D-glucanase for $50 \mathrm{~h}$ as described in Methods. Enzymic activity was destroyed by heating the reaction mixture at $100{ }^{\circ} \mathrm{C}$ for $5 \mathrm{~min}$. After cooling, the insoluble component was separated by centrifugation and accounted for $31 \%$ of the initial polysaccharide material. This residue will be referred to as $\mathrm{G}_{1-3}$ (see Fig. 6). The supernatant fraction was chromatographed on Bio-Gel P-2 (Fig. 2a). Two major peaks (A and B) and two minor peaks (C and D) of carbohydrate were found. Peak A (I5.2 mg) eluted with the void volume and was polysaccharide in nature. Peaks B $(24.6 \mathrm{mg}), \mathrm{C}(6.3 \mathrm{mg})$ and D $\left(7^{\circ} \mathrm{I} \mathrm{mg}\right)$ were identified as laminaritriose, laminaribiose and glucose respectively. 
On total acid hydrolysis, samples of peak A gave glucose $(87 \%)$ and mannose ( $13 \%$ ). On partial acid hydrolysis, glucose, gentiobiose, gentiotriose and gentiotetraose were the major products together with smaller amounts of laminaribiose, laminaritriose and mannose. As expected, peak $A$ was not hydrolysed by the endo- $(\mathrm{I} \rightarrow 3)-\beta$-D-glucanase but was degraded by the endo- $(\mathrm{I} \rightarrow 6)-\beta$-D-glucanase to give mainly glucose, gentiobiose, $3^{2}-\beta$-glucosylgentiobiose and the mixed-linkage tetrasaccharide $\left(R_{\mathrm{glc}} 0 \cdot \mathrm{I} 2\right)$. Traces of gentiotriose and mannose were also formed.

Peak A was subjected to further chromatographic examination in an attempt to determine its homogeneity. Samples of the material were excluded from Bio-Gel P-30 and P-I50 columns. Fractionation of peak A on Sepharose 6B chromatography (Fig. $3 a$ ) gave two incompletely resolved peaks, $\mathrm{E}$ and $\mathrm{F}$. Because of the considerable overlap, only the groups of fractions indicated (Fig. $3 a$ ) were combined for further examination. These are designated as groups I and 2. On total acid hydrolysis, samples from group I yielded $75 \%$ glucose and $25 \%$ mannose. Partial acid hydrolysis yielded predominantly glucose and gentiosaccharides together with smaller amounts of mannose. $(\mathrm{I} \rightarrow 3)-\beta$-D-Linked oligosaccharides or mannosaccharides were absent. It appears, therefore, that the first peak eluted from the Sepharose $6 \mathrm{~B}$ column was primarily a $(\mathrm{I} \rightarrow 6)-\beta$-D-linked glucan. It is not clear from these results whether mannose is covalently linked to this glucan.

Similar analysis of group 2 fractions (Fig. $3 a$ ) gave $85 \%$ glucose and $15 \%$ mannose. It is possible that this small percentage of mannose was a contamination from the preceding peak. Partial acid hydrolysates contained predominantly glucose and gentiobiose but no higher gentiosaccharides. Smaller amounts of the mixed-linkage oligosaccharides (Table I; $R_{\text {glc }} 0.3 \mathrm{I}$ and 0.12$)$ were also formed. These products are consistent with a sequeríce consisting of alternating $(\mathrm{I} \rightarrow 3)-\beta$ and $(\mathrm{I} \rightarrow 6)-\beta$-D linkages. The absence of laminaribiose in the hydrolysates is consistent with the lability of this linkage when adjacent to a $(\mathrm{I} \rightarrow 6)-\beta$-bond. Such a structure would also explain the presence of glucosylglycerol in the products of Smith degradation of the original glucan (Fleet \& Manners, 1976).

$(\mathrm{I} \rightarrow 6)-\beta$-D-glucanase hydrolysates. $\mathrm{G}_{1}(\mathrm{I} 00 \mathrm{mg}$ ) was hydrolysed with the endo-( $\mathrm{I} \rightarrow 6)-\beta-\mathrm{D}-$ glucanase for $50 \mathrm{~h}$. The insoluble undegraded material was isolated by centrifugation and will be referred to as $\mathrm{G}_{1-6}$ (yield $83.4 \mathrm{mg}$; see Fig. 6). The soluble hydrolysis products were concentrated and fractionated by chromatography on Bio-Gel P-2 (Fig. 4). Five main peaks $(\mathrm{G}, \mathrm{H}, \mathrm{J}, \mathrm{K}, \mathrm{L})$ of carbohydrate were resolved. Peaks $\mathrm{H}, \mathrm{J}, \mathrm{K}$ and $\mathrm{L}$ were identified respectively as gentiotetraose and mixed-linkage tetrasaccharide $\left(R_{\text {glo }} 0 \cdot 12\right)$; gentiotriose and $3^{2}$ - $\beta$-glucosylgentiobiose; gentiobiose; glucose. Peak $G$, which accounted for $1.85 \%$ of the original material, eluted with the void volume and samples of this fraction were also excluded from Bio-Gel P-30 and P-I 50 columns. Peak G was considered to be polysaccharide in nature and on acid hydrolysis gave mostly mannose with smaller amounts of glucose. Yields of this material were insufficient for further detailed examination.

\section{Characterization of $G_{1-3}$ and $G_{1-6}$}

As described above, these are the insoluble residues left after either $(\mathrm{I} \rightarrow 3)-\beta$ - or $(\mathrm{I} \rightarrow 6)-\beta$ D-glucanase hydrolysis of $\mathrm{G}_{1}$ preparations.

$G_{1-3}$. This material was not hydrolysed further by the endo-(I $\left.\rightarrow 3\right)-\beta$-D-glucanase; in addition, it was not hydrolysed by the endo-(I $\rightarrow 6)-\beta$-D-glucanase. Total acid hydrolysis gave only glucose. On partial acid hydrolysis, the following products were obtained: glucose $10+$, laminaribiose $4+$, laminaritriose $3+$, gentiobiose $3+$, laminaritetraose $2+$, laminaripentaose $2+$, gentiotriose $2+$, and higher unresolved oligosaccharides. As 


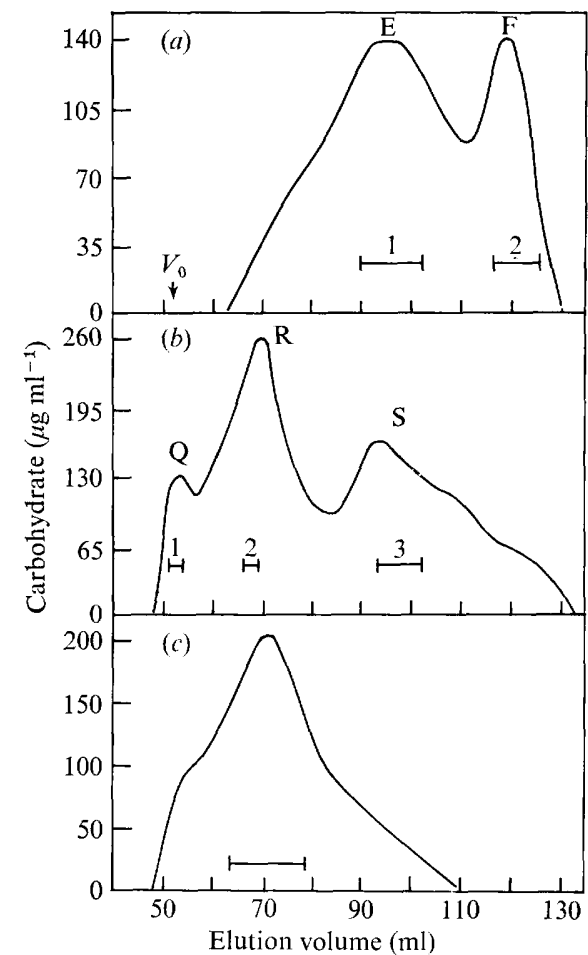

Fig. 3

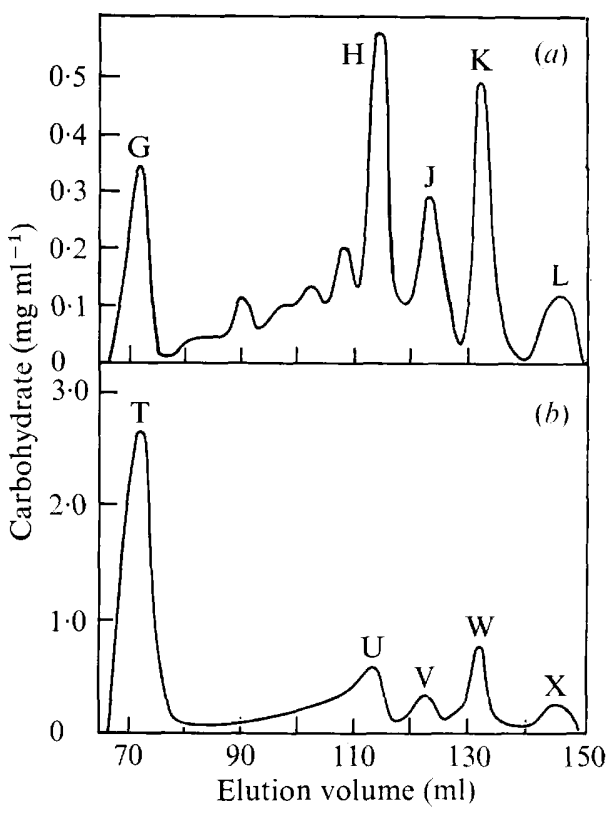

Fig. 4

Fig. 3. Sepharose 6B chromatography of (a) peak A (Fig. 2a), (b) peak M (Fig. 2c), (c) peak T (Fig. $4 b$ ).

Fig. 4. Bio-Gel P-2 chromatography of $(\mathrm{I} \rightarrow 6)-\beta$-D-glucanase hydrolysates of $(a) \mathrm{G}_{1}$ from $S$. cerevisiae NCYCI I09, (b) cell walls from $S$. cerevisiae NCYCI 109.

expected, methylation analysis (Table 2 ) showed a predominantly $(I \rightarrow 3)-\beta$-D-linked glucan with small percentages of branching and $(\mathrm{I} \rightarrow 6)-\beta$-D-linked residues. The degree of branching and proportion of $(\mathrm{I} \rightarrow 6)$ - $\beta$-D-linked residues were smaller than in the parent $\mathrm{G}_{1}$ molecule (see Table 2). The degraded molecule had a degree of polymerization (DP) of 270 (cf. 1330 for undegraded $G_{1}$ preparation) as determined by the sorbitol dehydrogenase method.

$G_{1-6}$. This material was not further hydrolysed by the $(\mathrm{I} \rightarrow 6)-\beta$-D-glucanase. However, it was extensively degraded by the $(\mathrm{I} \rightarrow 3)-\beta$-D-glucanase yielding an insoluble residue, as described previously for the hydrolysis of $G_{1}$ by this enzyme. Bio-Gel P-2 chromatography of the solubilized components gave the elution profile shown in Fig. $2(b)$. The products were similar to those described for Fig. $2(a)$ except that the excluded peak was much smaller. This is consistent with the evidence that the excluded peak was essentially a $(\mathrm{I} \rightarrow 6)$ - $\beta$-D-linked component. Methylation analysis of $\mathrm{G}_{1-6}$ (Table 2) again showed a predominantly $(\mathrm{I} \rightarrow 3)-\beta$-D-linked glucan. A small percentage (about $\mathrm{I} \%$ ) of $(\mathrm{I} \rightarrow 6)-\beta$-Dlinkages were resistant to enzymic hydrolysis. These probably occur as isolated di- or trisaccharide units in larger blocks of $(I \rightarrow 3)-\beta$-D-linked residues. This is consistent with the previous Smith degradation studies when fragmentation of $G_{1}$ was found (Fleet \& Manners, I976). $\mathrm{G}_{1-6}$ was very resistant to acid hydrolysis and so the DP could not be measured by the sorbitol_dehydrogenase method. 
Table 2. Methylation analysis of $G_{1}$ preparations after degradation by $(\mathrm{I} \rightarrow 3)-\beta$ - and $(\mathrm{I} \rightarrow 6)-\beta$-D-glucanases

\begin{tabular}{|c|c|c|c|c|}
\hline \multirow[b]{2}{*}{$\begin{array}{l}O \text {-Methyl-D-glucitol } \\
\text { acetate derivative }\end{array}$} & \multirow[b]{2}{*}{ Type of linkage } & \multicolumn{3}{|c|}{ Composition (mol \%) } \\
\hline & & $\mathrm{G}_{1-3}$ & $\mathrm{G}_{1-6}$ & $\mathrm{G}_{1}{ }^{*}$ \\
\hline $\begin{array}{l}\text { 2,3,4,6-Tetra- } \\
\text { 2,4,6-Tri- } \\
\text { 2,3,4-Tri- } \\
\text { 2,4-Di- }\end{array}$ & $\begin{array}{l}\text { Non-reducing end groups } \\
(\mathrm{I} \rightarrow 3) \text { - } \\
(\mathrm{I} \rightarrow 6) \text { - } \\
\text { Branch points at } \mathrm{C}-\mathrm{I}, \mathrm{C}-3 \text { and } \mathrm{C}-6\end{array}$ & $\begin{array}{r}3 \cdot 2 \\
93 \cdot 8 \\
1 \cdot 5 \\
1 \cdot 5\end{array}$ & $\begin{array}{r}2 \cdot 9 \\
93 \cdot 8 \\
1 \cdot 0 \\
2 \cdot 3\end{array}$ & $\begin{array}{r}3 \cdot 7 \\
84 \cdot 7 \\
8 \cdot 3 \\
3 \cdot 3\end{array}$ \\
\hline & * Data from Fleet \& Manners (197 & & & \\
\hline
\end{tabular}

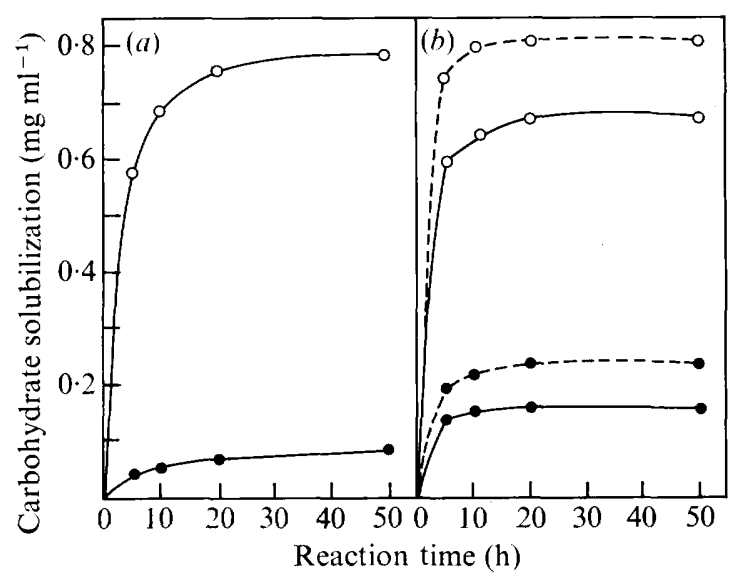

Fig. 5. The action of the $(\mathrm{I} \rightarrow 3)-\beta$-D-glucanase $(a)$ and the $(\mathrm{I} \rightarrow 6)-\beta$-D-glucanase $(b)$ on isolated cell walls of $S$. cerevisiae NCYCI I09. The broken lines show the action of a mixture of the two enzymes. $\bullet$, Release of reducing groups; $O$, total solubilization of carbohydrate.

Action of the $(\mathrm{I} \rightarrow 3)-\beta$ - and $(\mathrm{I} \rightarrow 6)-\beta$-D-glucanases on cell walls of $S$. cerevisiae NCYCI I09

Cell walls were hydrolysed with either the $(\mathrm{I} \rightarrow 3)-\beta$ - or $(\mathrm{I} \rightarrow 6)-\beta$-D-glucanase or with a combination of the two enzymes (Figs 5 and 6). Very little degradation was apparent with either enzyme system when hydrolysis was monitored only by the release of reducing groups. However, total carbohydrate solubilization was much higher (up to one third of the initial wall material after $50 \mathrm{~h}$ ) suggesting that mostly large molecules were being released during enzymic degradation. The monosaccharide composition of the solubilized carbohydrate, examined by total acid hydrolysis, was $70 \%$ glucose and $30 \%$ mannose for the $(\mathrm{I} \rightarrow 3)-\beta$-Dglucanase hydrolysate and $60 \%$ glucose and $40 \%$ mannose for the $(\mathrm{I} \rightarrow 6)-\beta$-D-glucanase hydrolysate.

\section{Nature of the solubilized products}

Examination by paper chromatography indicated that these were the same as those obtained from the corresponding hydrolyses of the alkali-soluble $G_{1}$ preparations from the cell wall (Table I and Fig. 6). To identify the higher molecular weight species, largescale enzymic digestions ( $300 \mathrm{mg}$ cell walls) were prepared. After hydrolysis for $56 \mathrm{~h}$, the remaining insoluble material was removed by centrifugation and the supernatant was concentrated and fractionated by gel chromatography. 


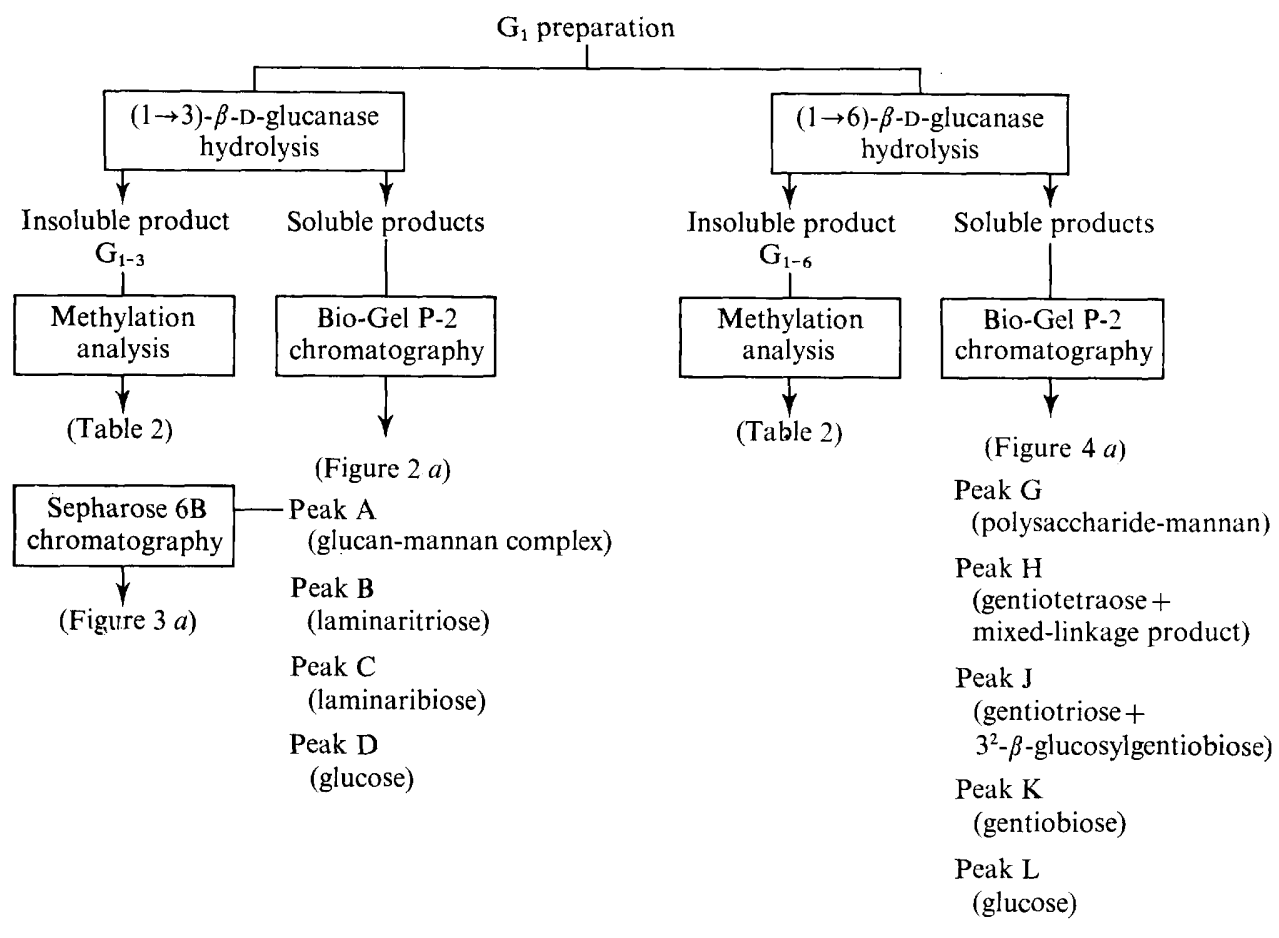

Isolated cell walls of

S. cerevisiae NCYC 1109

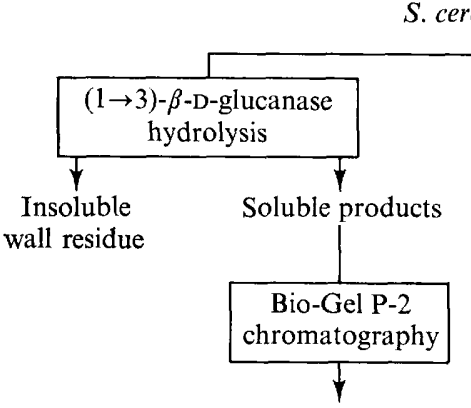

(Figure 2c)

Sepharose 6B chromatography

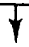

(Figure $3 b$ )
Peak M

(glucan-mannan complex)

Peak N

(laminaritriose)

Peak $\mathrm{O}$

(laminaribiose)

Peak $\mathbf{P}$

(glucose)

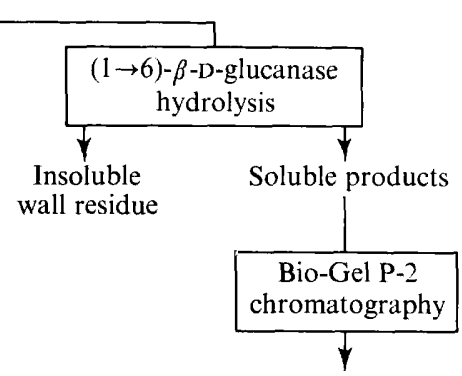

(Figure $4 b$ )

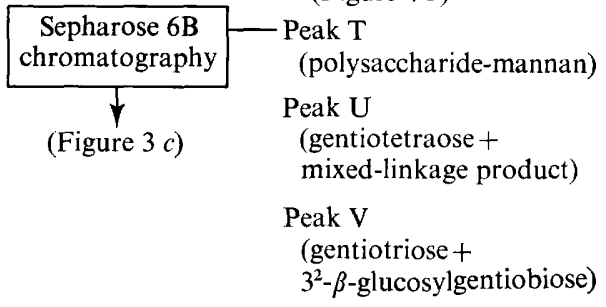

Peak W

(gentiobiose)

Peak X

(glucose)

Fig. 6. Flow diagrams for the analysis of $G_{1}$ and cell-wall enzyme hydrolysates. 
$(\mathrm{I} \rightarrow 3)-\beta$-D-glucanase hydrolysate. The elution profile on Bio-Gel P-2 chromatography is shown in Fig. $2(c)$. Most of the carbohydrate solubilized from the cell walls was excluded from the column (peak M) and was polysaccharide in nature (cf. Fig. 2a). Peaks N, O and $\mathrm{P}$ were identified as laminaritriose, laminaribiose and glucose respectively. Total acid hydrolysis of peak $M$ fractions liberated $36 \%$ glucose and $64 \%$ mannose. Peak $M$ was fractionated further by Sepharose $6 \mathrm{~B}$ chromatography and the results are presented in Fig. $3(b)$ so that they can be compared with the fractionation of the $\mathrm{G}_{1}(\mathrm{I} \rightarrow 3)-\beta$-D-glucanase hydrolysate (Fig. $3 a$ ). Three overlapping peaks $\mathrm{Q}, \mathrm{R}$ and $\mathrm{S}$ were obtained and representative fractions (indicated in Fig. $3 b$ ) were combined and examined. The contents of glucose and mannose in total acid hydrolysates of each group of fractions were: group $1,16 \%$ glucose, $84 \%$ mannose; group 2, $7 \%$ glucose, $93 \%$ mannose; group 3, $50 \%$ glucose, $50 \%$ mannose. Because of its high glucan content, a sample of group 3 was incubated with the $(\mathrm{I} \rightarrow 6)-\beta$-D-glucanase. Gentiosaccharides were released in substantial quantities suggesting that the glucan component of this polysaccharide fraction was predominantly $(\mathrm{I} \rightarrow 6)$ - $\beta$-D-linked. This polysaccharide peak, therefore, is similar in composition to peak E of Fig. 3(a); both peaks eluted in the same position.

$(\mathrm{I} \rightarrow 6)-\beta$-D-glucanase hydrolysate. The elution profile on Bio-Gel P-2 chromatography of this digest is presented in Fig. $4(b)$. Most of the solubilized polysaccharide was excluded from the column (peak T). Peaks U, V, W and X were identified as the same as the corresponding peaks in Fig. 4(a). Acid hydrolysis of peak T gave $3 \%$ glucose and $97 \%$ mannose. Peak $\mathrm{T}$ gave rise to a disperse peak on Sepharose $6 \mathrm{~B}$ chromatography (Fig. $3 \mathrm{c}$ ). Hydrolysis of the fractions indicated in Fig. $3(c)$ liberated $2 \%$ glucose and $98 \%$ mannose. This polysaccharide peak is probably similar to the corresponding peak in Fig. $3(b)$.

\section{Protein release from cell walls on glucanase hydrolysis}

The protein solubilized by glucanase action was determined using the material excluded from the Bio-Gel P-2 columns. Allowances were made for the added glucanase protein which was also excluded from these columns. However, the action of the glucanase caused the solubilization of only trace amounts of cell-wall protein. From $300 \mathrm{mg}$ cell-wall material, the $(\mathrm{I} \rightarrow 3)-\beta$-D-glucanase solubilized only $250 \mu \mathrm{g}$ protein while the $(\mathrm{I} \rightarrow 6)-\beta$-D-glucanase gave $650 \mu \mathrm{g}$.

\section{Cell-wall composition after glucanase hydrolysis}

Glucose was the main monosaccharide component of the insoluble cell-wall material left after glucanase hydrolysis. However, these wall residues (from either enzyme treatment) still contained 15 to $20 \%$ mannose, indicating that the cell-wall mannan was not completely removed by the action of the glucanases.

\section{DISCUSSION}

\section{Structure of the alkali-soluble glucan}

In our previous paper (Fleet \& Manners, 1976), the alkali-soluble glucan from the cell walls of $S$. cerevisiae NCYCI IOg was characterized as a molecule containing approximately $\mathrm{I} 330$ glucose residues, with $85 \%(\mathrm{I} \rightarrow 3)-\beta$-D linkages, $8 \%(\mathrm{I} \rightarrow 6)-\beta$-D linkages and $3 \%$ of residues triply-linked through C-I, C- 3 and C-6. The glucan also contained I to $2 \%$ mannose residues. Any interpretation of the fine structure of this macromolecule, however, is limited by the assumptions which must be made about its purity. In the absence of any evidence for heterogeneity for this glucan (Fleet \& Manners, 1976), it will be assumed that both the $(\mathrm{I} \rightarrow 3)-\beta$-D linkages and the $(\mathrm{I} \rightarrow 6)-\beta$-D linkages are present in the same molecule. 
Similarly, it will be assumed that the small amount of mannose present is not due to contamination by the cell-wall mannan component (Phaff, I97I) although this possibility cannot be entirely eliminated at this stage.

The alkali-soluble glucan was extensively degraded by the $(\mathrm{I} \rightarrow 3)-\beta$-D-glucanase with the liberation of laminarisaccharides, glucose and small amounts of gentiotriose. Hence the molecule contained a substantial proportion of $(\mathrm{I} \rightarrow 3)-\beta$-D-linked residues. The enzyme also released a soluble polysaccharide fraction (peak A, Fig. 2) which was heterogeneous (Fig. $3 a$ ). The major component of this polysaccharide fraction (peak E, Fig. $3 a$ ) contained $(\mathrm{I} \rightarrow 6)-\beta$-D-linked residues since gentiosaccharides were liberated both on partial acid hydrolysis and on enzymic digestion with a $(\mathrm{I} \rightarrow 6)-\beta$-D-glucanase. Mannose, which accounted for virtually all of the mannose in the original glucan, was also found in total acid hydrolysates of this peak. Whether peak $\mathrm{E}$ is a covalently-linked glucomannan complex is not clear from the data, since glucose-mannose oligosaccharides were not detected in partial acid hydrolysates. However, in view of the small amounts of mannose present in the original glucan molecule (I5 to 25 residues), such oligosaccharides could have been overlooked.

The action of the $(\mathrm{I} \rightarrow 3)-\beta$-D-glucanase also yielded a resistant fraction $\mathrm{G}_{1-3}$ in 25 to $30 \%$ yield. This fraction which had an apparent DP of 270 contained $94 \%$ ( $\rightarrow 3)$-linked, $\mathrm{I} \cdot 5 \%(\mathrm{I} \rightarrow 6)$-linked and $\mathrm{I} \cdot 5 \%$ triply-linked glucose residues. Thus, four branch points were present in this fragment. Some of the $(\mathrm{I} \rightarrow 6)$-linked residues were adjacent, since gentiobiose and gentiotriose were found in partial acid hydrolysates. Despite the very high proportion of $(I \rightarrow 3)$ linkages, $G_{1-3}$ was not further hydrolysed by the $(I \rightarrow 3)$-glucanase. This observation could relate to the physical state of the molecule (see Rees, I973). The alkaliinsoluble $(\mathrm{I} \rightarrow 3)-\beta$-D-linked glucan of baker's yeast cell walls (Manners et al., 1973a) was also largely resistant to the action of this particular glucanase (Fig. I $d$ ). The resistant $\mathrm{G}_{\mathbf{1 - 3}}$ fraction may represent the 'core' of the alkali-soluble glucan.

The action of the $(\mathrm{I} \rightarrow 6)-\beta$-D-glucanase on the alkali-soluble glucan was much less than the $(\mathrm{I} \rightarrow 3)-\beta$-D-glucanase (Fig. I), as expected from the ratio of the two types of linkages present in the molecule. The soluble products of hydrolysis were gentio- and mixed-linkage oligosaccharides and a soluble polysaccharide fraction (peak G, Fig. 4), which produced predominantly mannose with minor amounts of glucose on total acid hydrolysis. Thus, hydrolysis of the alkali-soluble glucan with the $(\mathrm{I} \rightarrow 6)-\beta$-D-glucanase releases and solubilizes the associated mannan material. This observation combined with the finding of a possible $(I \rightarrow 6)-\beta$-D-glucan-mannan complex (peak E, Fig. 3) suggests that some $(I \rightarrow 6)$ linked D-glucose residues are involved in the association of a mannan fragment with the predominantly $(\mathrm{I} \rightarrow 3)-\beta$-D-linked glucan.

The major product of $(\mathrm{I} \rightarrow 6)-\beta$-D-glucanase action on the glucan was the resistant fraction $\mathrm{G}_{1-6}$ (yield $83 \%$ ). This material was shown by methylation analysis (Table 2 ) to be similar in composition to $\mathrm{G}_{1-3}$. The small percentage of $(\mathrm{I} \rightarrow 6)$-linked residues which survived the $(\mathrm{I} \rightarrow 6)-\beta$-D-glucanase hydrolysis, and remained in $\mathrm{G}_{1-6}$ are probably dispersed as occasional di- and trisaccharide units among larger blocks of $(\mathrm{I} \rightarrow 3)$-linked residues. This would be consistent with the observed fragmentation pattern of the glucan on Smith degradation (Fleet \& Manners, 1976).

The overall structure of the alkali-soluble glucan that emerges is of a macromolecule with a $(\mathrm{I} \rightarrow 3)$ - $\beta$-D-glucan type 'core' having a low degree of branching (about $2 \cdot 0 \%$ ). The 'core' also contains occasional $(\mathrm{I} \rightarrow 6)$-linked residues. To this 'core' are attached mainly $(\mathrm{I} \rightarrow 3)-\beta$-D-linked side chains which may contain secondary branching, also in the form of $(\mathrm{I} \rightarrow 3)$-linked side chains. This would represent the structure remaining after the 
$(\mathrm{I} \rightarrow 6)$ - $\beta$-D-glucanase hydrolysis. The $(\mathrm{I} \rightarrow 3)-\beta$-D-linked side chains represent the proportion of the molecule susceptible to $(I \rightarrow 3)-\beta$-D-glucanase cleavage. Of the 1330 residues present in the original glucan, about $40(3 \%)$ are branch points. Side chains containing either mainly $(I \rightarrow 6)$-linked residues or a mixture of $(I \rightarrow 6)$-linked and $(I \rightarrow 3)$-linked residues (peaks E and F, Fig. 3) are also present in the molecule and these may be attached to the $(\mathrm{I} \rightarrow 3)$-linked side chains described above since they are released by $(\mathrm{I} \rightarrow 3)-\beta$-D-glucanase hydrolysis. However, as there are only about 100 residues in the glucan $(8 \%)$ which are linked solely C-I-C-6, the number of such side chains would be very few indeed.

The alkali-soluble glucan as isolated always contains a fragment of the cell-wall mannan component which can be released by hydrolysis with the $(\mathrm{I} \rightarrow 6)-\beta$-D-glucanase. If this fragment is covalently linked to the glucan, it would appear from our results that $(\mathrm{I} \rightarrow 6)$ linked $\beta$-D-glucose residues are involved in this function. Glucomannan complexes obtained by the alkali-extraction of cell walls of $S$. cerevisiae have been described previously (Kessler \& Nickerson, 1959) but their structures were not reported.

\section{Action of the Bacillus circulans WL-I2 glucanases on the cell walls of S. cerevisiae NCYCI 109}

In a previous paper (Kopecká, Phaff \& Fleet, I974), the actions of the endo-(I $\rightarrow 3)-\beta$-Dglucanase and the endo-(I $\rightarrow 6)-\beta$-D-glucanase on isolated cell walls of $S$. cerevisiae were studied using the electron microscope. These enzymes, acting singly or in combination, brought about the removal of an amorphous surface layer from the cell walls to reveal bud scars and a fibrillar glucan network. The present investigation has focused on the chemical changes of this reaction. Although the two enzymes did not produce any visible lysis of $S$. cerevisiae cell walls (cf. Tanaka \& Phaff, 1965; Fleet \& Phaff, 1974a), they nevertheless caused 30 to $40 \%$ solubilization of the cell-wall polysaccharide material. The products of hydrolysis from the action of either enzyme were a mixture of polysaccharide and oligosaccharide components. The nature of the oligosaccharide products clearly indicated that $(\mathrm{I} \rightarrow 3)$ - and $(\mathrm{I} \rightarrow 6)-\beta$-D-glucosidic linkages within the cell wall had been cleaved. The following discussion will show that these linkages probably formed part of the alkali-soluble glucan fraction of the wall.

The $(\mathrm{I} \rightarrow 3)-\beta$-D-glucanase was more effective at hydrolysing the cell wall than the $(\mathrm{I} \rightarrow 6)$ $\beta$-D-glucanase and this is consistent with the action of these enzymes on the alkali-soluble glucan (Figs $I$ and 5). The glucose-containing products of cell-wall hydrolysis by the $(\mathrm{I} \rightarrow 3)-\beta$-D-glucanase accounted for about $20 \%$ of the cell-wall material, which corresponds approximately with the wall content of alkali-soluble glucan (Eddy \& Woodhead, I968; Fleet \& Manners, 1976). The oligosaccharide products of cell-wall hydrolysis from either enzyme were identical to those obtained by the action of these enzymes on the isolated alkali-soluble glucan (Table I), strongly suggesting that this glucan is the site of enzyme action in intact cell walls.

The polysaccharide products of $(\mathrm{I} \rightarrow 3)-\beta$-D-glucanase action on the walls were heterogeneous and included some predominantly mannan-containing components (Fig. 3 b). One of these components, however, (peak S, Fig. $3 b$ ) contained equal amounts of glucan and mannan and the glucan fraction contained a high proportion of $(\mathrm{I} \rightarrow 6)-\beta$-D-linkages. This association of $(\mathrm{I} \rightarrow 6)-\beta$-D-glucan and mannan is similar to that found in peak $\mathrm{E}$ (Fig. $3 a$ ) which was obtained by the hydrolysis of isolated alkali-soluble glucan with $(\mathrm{I} \rightarrow 3)-\beta$-Dglucanase. The polysaccharide products of $(\mathrm{I} \rightarrow 6)-\beta$-D-glucanase action on the cell walls were mostly mannan-containing components, but, as expected, the glucan-mannan component (peak S, Fig. $3 b$ ) was absent since the glucan moiety would have been degraded. 
Bacon et al. (1969) have previously described the solubilization of cell-wall mannan material by the action of an endo-( $\mathrm{I} \rightarrow 6)-\beta$-D-glucanase. Collectively, these separate observations suggest an association of the cell-wall mannan with some $(1 \rightarrow 6)$-linked $\beta$-D-glucose residues.

The heterogeneity of the mannan components obtained on gel filtration of the wall hydrolysates coupled with the fact that not all of the cell-wall mannan was removed by enzyme action is consistent with the view of Ballou (I974) that yeast cell walls contain a variety of different mannan molecules.

Overall, our results show that a large proportion of the yeast cell-wall mannan is attached to the cell wall through a glucan component since degradation of isolated walls by either $(\mathrm{I} \rightarrow 3)-\beta$-D-glucanase or $(\mathrm{I} \rightarrow 6)-\beta$-D-glucanase releases this polysaccharide. On isolation, the alkali-soluble glucan component of the cell wall contains an associated mannan fragment (Fleet \& Manners, 1976). This fragment, which probably represents a remnant of the wall mannan component, is released by either $(\mathrm{I} \rightarrow 3)-\beta$-D- or $(\mathrm{I} \rightarrow 6)-\beta$-D-glucanase hydrolysis. The other products of glucanase action on isolated cell walls or alkali-soluble glucan preparations are very similar. It appears from these data, therefore, that the alkali-soluble glucan component of the yeast cell wall, originally described by Eddy \& Woodhead (I968) and subsequently studied by us (Fleet \& Manners, 1976), is closely associated with some parts of the mannan component. Furthermore, the association of mannan and ( $\mathrm{I} \rightarrow 6)-\beta$-Dlinked glucan in the products of $(\mathrm{I} \rightarrow 3)-\beta$-D-glucanase degradation of either cell walls or preparations of alkali-soluble glucan suggests that some $(\mathrm{I} \rightarrow 6)$-linked $\beta$-D-glucose residues may be involved in this association of mannan with glucan. If this is so, the detailed chemistry of this association merits investigation, and could perhaps be resolved by a more thorough analysis of the glucan-mannan fragments reported in this study.

We are indebted to the Science Research Council for financial support for G.H.F.

\section{REFERENCES}

BACON, J. S. D., FARmer, V. C., Jones, D. \& TAYLOR, I. F. (I969). The glucan components of the cell wall of baker's yeast (Saccharomyces cerevisiae) considered in relation to its ultrastructure. Biochemical Journal II4, 557-576.

BALLOU, C. E. (1974). Some aspects of the structure, immunochemistry and genetic control of yeast mannans. Advances in Enzymology 40, 239-270.

Dubois, M., Gilles, K. A., Hamilton, J. K., Rebers, P. A. \& Smith, F. (1956). Colorimetric method for determination of sugars and related substances. Analytical Chemistry 28, 350-356.

EDDY, A. A. \& WoOdHEAD, J. S. (1968). An alkali-soluble glucan fraction from the cell walls of the yeast Saccharomyces carlsbergensis. FEBS Letters $\mathbf{1}, 67-68$.

FLeEt, G. H. \& MANNERS, D. J. (1975). The use of enzymes in the study of yeast cell wall composition and structure. In Abstracts, Fourth International Symposium on Yeast and Other Protoplasts, Nottingham, p. 67.

FLeET, G. H. \& MANNERS, D. J. (1976). Isolation and composition of an alkali-soluble glucan from the cell walls of Saccharomyces cerevisiae. Journal of General Microbiology 94, I80-192.

FleEt, G. H. \& PhAfF, H. J. (1974a). Lysis of yeast cell walls: glucanases from Bacillus circulans wh-1 2. Journal of Bacteriology I19, 207-219.

Fleet, G. H. \& PhafF, H. J. (1974b). Glucanases in Schizosaccharomyces. Isolation and properties of the cell wall-associated $\beta$ - $(\mathrm{I} \rightarrow 3)$-glucanases. Journal of Biological Chemistry 249, 17 1 7-1 728.

Hellerqvist, C. G., LindBerg, B. \& SAMuelsSon, K. (1968). Methylation analysis of pustulan. Acta chemica scandanavica 22, 2736-2737.

KESSLER, G. \& NICKERSON, W. J. (1959). Glucomannan-protein complexes from cell walls of yeasts. Journal of Biological Chemistry 234, 2281-2283.

KopeCKÁ, M., PHAFF, H. J. \& FLeET, G. (I973). Demonstration of a fibrillar component in the cell wall of the yeast Saccharomyces cerevisiae and its chemical nature. Journal of Cell Biology 62, 66-76. 
Lowry, O. H., Rosebrough, N. J., Farr, A. L. \& Randall, R. J. (I95I). Protein measurement with the Folin phenol reagent. Journal of Biological Chemistry 193, 265-275.

Manners, D. J., Masson, A. J. \& Patterson, J. C. (I973a). The structure of a $\beta$-(I $\rightarrow 3$ )-D-glucan from yeast cell walls. Biochemical Journal r35, 19-30.

Manners, D. J., Masson, A. J., Patterson, J. C., Bjorndal, H. \& Lindberg, B. (1973 $b$ ). The structure of a $\beta-(\mathrm{I} \rightarrow 6)$-D-glucan from yeast cell walls. Biochemical Journal 135, $3 \mathrm{I}-36$.

Nakamura, N. \& TANABE, O. (I963). Studies on an enzyme capable of splitting $\beta$-D-(1 $\rightarrow 6$ )-glucosidic linkage. I. Isolation of a lutease producing micro-organism and some properties of lutease. Agricultural and Biological Chemistry 27, 80-87.

Peat, S., Whelan, W. J. \& Edwards, T. E. (I958). Polysaccharides of baker's yeast. Part II. Yeast glucan. Journal of the Chemical Society, 3862-3868.

Phaff, H. J. (197I). Structure and biosynthesis of the yeast cell envelope. In The Yeasts-Physiology and Biochemistry of Yeasts, vol. 2, pp. I 35-210. Edited by A. H. Rose and J. S. Harrison. London and New York: Academic Press.

REEs, D. A. (1973). Polysaccharide conformation. In Carbohydrates, MTP International Review of Science: Organic Chemistry, series I, vol. 7, pp. 25I-283. Edited by G. O. Aspinall. London: Butterworths.

TANakA, H. \& Phaff, H. J. (1965). Enzymic hydrolysis of yeast cell walls. I. Isolation of wall-decomposing organisms and separation and purification of lytic enzymes. Journal of Bacteriology 89, I570-1 580. 